\title{
DIGITALISASI SISTEM MANAJEMEN MUTU ISO BERBASIS APLIKASI WEB
}

\author{
Purnomo Hadi Susilo', M. Ghofar Rohman' \\ 1,2 Dosen Program Studi Teknik Informatika, Fakultas Teknik, Universitas Islam Lamongan \\ Jl. Veteran No. 53 A Lamongan \\ Telp. (0322) 324706 \\ E-mail: hadyjelak.purnomo@gmail.com ${ }^{1}$,ghofar.kit@gmail.com ${ }^{2}$
}

\begin{abstract}
Control and distribution of documents is a problem that often occurs in an institution/company that has implemented a Quality Management System (QMS) ISO. Solutions that can be done is to change conventional management into digital management through information technology that is able to distribute information quickly, accurately and in real time. This study aims to determine the level of use, efficiency, effectiveness, and satisfaction of users of the product to be built. The results of this study indicate that the products have been built to improve the efficiency and effectiveness of the performance of the user who serves as the perpetrators of ISO management, and can be used as a solution to get the ISO quality management is more reliable in the era of digitalization.
\end{abstract}

Keywords: digital, quality management, ISO, web application.

\section{PENDAHULUAN}

Usaha pemerintah Indonesia dalam meningkatkan kualitas pendidikan merupakan sebuah permasalahan yang masih ditangani sampai saat ini. Hal ini terjadi karena pengelolaan manajemen pendidikan yang dilakukan belum dilaksanakan secara profesional, termasuk dalam pendidikan kejuruan. Manajemen pendidikan kejuruan yang profesional merupakan sebuah manajemen yang bersifat cerdas serta mampu melaksanakan fungsi-fungsi manajemen (planing, doing, checking, dan reviewing), sehingga tujuan pendidikan dapat dicapai dengan efektif dan efisien (Sugiyono, 2003:21). Depdikbud (1997:5) mempunyai target bahwa menjelang 2020 yaitu terwujudnya 100 lembaga SMK (Sekolah Menengah Kejuruan) bertaraf internasional dan 500 SMK bertaraf nasional. Syarat SMK yang bertaraf internasional adalah dengan menerapkan manajemen mutu yang internasional yaitu ISO (Depdiknas, 2002:13). Uraian di atas menjelaskan bahwa untuk meningkatkan kualitas pendidikan kejuruan yang bertaraf internasional, maka yang dapat dilakukan yaitu dengan mengadopsi sebuah manajemen mutu yang bertaraf internasional yakni Sistem Manajemen Mutu (SMM) ISO 9001:2008.

Badan standarisasi bertaraf internasional yang telah diakui untuk sertifikasi manajemen mutu dalam pendidikan yang telah diterapkan yaitu SMM ISO 9001:2008. Tampubolon (2001:108) menjelaskan bahwa mutu merupakan intruksi sifat-sifat sebuah produk yang menggambarkan kemampuannya dalam memenuhi kebutuhan pelanggan secara langsung ataupun tidak langsung, tersurat maupun tersirat, masa kini dan masa depan. Inti pokok dalam penyelenggaraan pendidikan yaitu sebuah peningkatan dan penjaminan mutu pendidikan. Hal ini dilakukan sebagai upaya menjawab daya saing, pencitraan kepada masyarakat, dan akuntabilitas pendidikan.

Penerapan SMM ISO 9001:2008 pada dunia pendidikan khususnya SMK adalah sebuah terobosan yang dapat dilakukan untuk meningkatkan kualitas dan mutu pendidikan, sehingga para lulusan SMK nantinya dapat terserap dengan baik di dunia usaha atau industri bahkan perguruan tinggi. Hal ini sesuai dengan penyataan [3]Sonhadji (2013:194) bahwa untuk menciptakan SDM yang berkualitas dapat dicapai dengan melakukan pendidikan yang berkualitas pula, didukung dengan semua komponen pendidikan (masukan, proses, luaran dan outcome), serta harus memenuhi memenuhi standar kualitas dan manajemennya juga harus berkualitas.

Permasalahan umum yang sering terjadi saat menerapkan SMM ISO 9001:2008 yaitu pengendalian dan pendistribusian dokumen kepada seluruh pelaku manajemen. Hal ini terjadi karena terdapat kerumitan interaksi proses di dalamnya, sehingga pengendalian dokumen dilakukan tidak sesuai dengan instruksi kerja atau SOP yang telah diterapkan. Kerumitan interaksi proses tersebut yaitu: 1) proses pemberian persetujuan; 2) proses 
peninjauan dan memperbaharui dokumen; 3) proses identifikasi atas perubahan dan status revisi terakhir dokumen; 4) proses pemastian bahwa revisi sesuai dari dokumen yang berlaku dan tersedia ditempat pemakaian; 5) proses pemastian bahwa dokumen tersebut sah serta dapat mudah diidentifikasi; dan 6) proses pemastian bahwa dokumen asli eksternal dapat diidentifikasi dan terkendali distribusinya. Permasalahan tersebut terjadi karena proses pendistribusian dokumen seharusnya dilakukan sesegera mungkin saat ada pembaharuan sebuah dokumen, padaha proses tersebut tidak mungkin dapat dilakukan jika masih dikerjakan secara konvensional. Solusi yang dapat dilakukan yaitu dengan mengubah proses pengendalian dokumen tersebut yakni dengan menerapkan sistem digitalisasi yang lebih handal.

Perkembangan teknologi informasi yang semakin handal merupakan alasan utama berubahnya era konvensional menuju era digital. Hal ini dikarenakan pada era konvensinal semua jenis pekerjaan harus dilakukan dengan membutuhkan waktu yang panjang, sedangakan di era digital segala sesuatunya dapat dilakukan dengan cepat bahkan dalam hitungan detik. Indrajit (2015:1) menjelaskan bahwa pada jaman dahulu bisa memakan waktu yang lama untuk mengola sebuah data atau informasi sebelum dikirimkan kesisi lain di dunia, sedangakan pada era digital dapat dilakukan hanya dalam hitungan detik. Hal ini merupakan sebuah bukti bahwa terdapat pergeseran dari era konvensional menuju era digital dan segala sesuatunya dapat dilakukan dengan cepat.

Berkembangnya teknologi digital (terkomputerisasi) yang diintegrasikan dengan telekomunikasi telah membawa manusia memasuki masa-masa revolusinya. Penggabungan antara teknologi komputer dengan telekomunikasi telah menjadikan suatu perubahan dibidang sistem informasi (Indrajit, 2015:1). Melalui sistem informasi (SI), manusia dapat memperoleh segala macam informasi yang dibutuhkan dengan lebih efektif dan efesien. Menurut Wahyono (2004:2) menjelaskan bahwa SI adalah sistem pembangkit sebuah informasi dengan integrasi yang dimiliki antar sub-system nya dan dapat menyediakan informasi yang berkualitas, tepat, cepat dan akurat sesuai dengan manajemen yang membutuhkannya.
SI mempunyai peran penting dalam pengendalian manajemen dalam suatu organisasi. Hal ini karena tujuan utama pengendalian manajemen adalah membantu manajemen dalam mengkoordinasi beberapa sub-unit dari golongan dan mengarahkan beberapa bagian tersebut dalam mencapai suatu tujuan (Wahyono, 2004:5). Ada dua hal yang perlu diperhatikan dari definisi tersebut, yaitu mengkoordinasi dan mengarahkan. Agar proses tersebut dapat berjalan dengan baik, maka dua proses tersebut memerlukan suatu sistem agar proses koordinasi dan pengarahan bisa berjalan dengan efektif dan efisien sehingga tujuan yang telah direncanakan dapat tercapai.

Terdapat beberapa manfaat utama perkembangan SI untuk pengendalian manajemen, yaitu: 1) penghematan waktu (time saving); 2) penghematan biaya (cost saving); 3) peningkatan efektifitas (efectiveness); 4) pengembangan teknologi (technology development); dan 5) pengembangan personal akuntansi (accounting staff development) (Wahyono, 2004:5). Beberapa manfaat utama pengembangan SI tersebut menunjukkan bahwa dengan didukung SI, maka pengendalian manajemen khususnya SMM ISO dapat dilakukan dengan efektif dan efesien. Dukungan aplikasi web pada SI dapat menambah tingkat efektifitas dan efisiensi pada SI itu sendiri, karena dengan aplikasi web seluruh informasi yang ada pada SI bisa diakses oleh banyak pengguna secara bersamaan.

Tujuan khusus dalam penelitian ini antara lain yaitu: (1) Menghasilkan sistem pengendalian dokumen ISO baru, yaitu dengan mengembangkan SMM ISO digital berbasis aplikasi web yang terintegrasi dengan basisdata MySQL; (2) Mengukur tingkat kegunaan aplikasi yang dikembangkan sebagai solusi alternatif pengendalian dokumen ISO; (3) Mengetahui tingkat efisiensi aplikasi yang telah dikembangkan setelah digunakan; Mengetahui tingkat efektifitas aplikasi yang dikembangkan saat diterapkan secara realtime; dan (5) Mengetahui tingkat kepuasan pengguna aplikasi terhadap aplikasi yang dikembangkan.

Menurut para pekerja pada suatu organisasi, Sistem informasi (SI) biasanya hanya digunakan untuk memperoleh dan mengolah sebuah informasi. SI mempunyai katerkaitan yang sangat erat dengan Teknologi Informasi (TI). Terkait dengan TI, SI lebih rumit dan hanya bisa difahami dengan melihatnya dari 
perspektif teknologi. Menurut Kadir (2003: 546), SI adalah kombinasi antara prosedur kerja, informasi, orang, dan TI yang saling diintegrasikan untuk mencapai tujuan dalam sebuah organisasi.

SI adalah sekumpulan komponen yang saling berhubungan, mengumpulkan, memproses, menyimpan, dan mendistribusikan sebuah informasi sebagai penunjang pengambilan keputusan dan pengawasan dalam organisasi (Laudon, 2007: 5). SI mempunyai peran sebagai sumber informasi yang dibutuhkan organisasi untuk menciptakan keputusan, pengendalian operasi, menganalisis permasalahan dan menciptakan produk baru. Kesimpulanya, SI adalah suatu sistem dalam organisasi, yang mempertemukan kebutuhan pengolahan transaksi harian, mendukung operasi (manajerial) dan kegiatan strategi dalam organisasi dan menyediakan pihak luar tertentu dengan laporan-laporan yang diperlukan (Supriyanto, 2007: 243).

Penjelasan di atas menunjukkan bahwa SI merupakan sekumpulan komponen-komponen yang saling berkorelasi berbasis komputer maupun manual dan dibuat untuk mengumpulkan, menyimpan, mengelola data, memproduksi informasi serta pendistribusikannya kepada seluruh pemakai informasi tersebut. Fungsi lain dari SI yaitu untuk mencapai tujuan-tujuan tersebut dan biasanya digunakan untuk membantu dalam menganalisa permasalahan serta pengambilan sebuah keputusan.

Basisdata MySQL merupakan salah satu dari sekian aplikasi basisdata yang dapat didigabungkan menjadi satu dengan aplikasi Web. Fungsi aplikasi MySQL yang terintegrasi dengan aplikasi Web yaitu sebagai media penyimpanan seluruh data yang dibutuhkan pada aplikasi Web yang dikembangkan agar aplikasi Web yang dibangun bisa lebih fleksibel dan bisa memenuhi kebutuhan yang diminta oleh user. Menurut Nugroho (2005:1), MySQL adalah salah satu program basisdata server yang mampu menerima dan mengirim sekumpulan data dengan kemampuan yang sangat cepat, multi user serta menggunakan perintah standar SQL.

Uraian di atas menjelaskan bahwa $M y S Q L$ adalah salah satu dari sekian basisdata client/server yang mampu menangani beberapa user serta mampu menangani beberapa intruksi sekaligus dalam satu waktu akses yang bersamaan. Sistem MySQL akan merekam seluruh data user dalam sebuah tabel user yang berada dalam basisdata yang bernama MySQL. $M y S Q L$ dikembang dengan baik oleh pengembangnya sehingga $M y S Q L$ dapat dioperasikan pada semua jenis sistem operasi, termasuk Windows.

Pengujian sebuah aplikasi atau sistem agar aplikasi mampu dioperasikan sesuai kebutuhan pengguna, maka dapat dilakukan dengan menggunakan metode usability testing atau uji ketergunaan. Menurut Rahadi (2014:664), menjelaskan bahwa usability merupakan suatu metode yang dapat digunakan untuk meningkatkan kemudahan pemakaian selama proses desain. Usability mengacu pada bagaimana pengguna dapat mempelajari dan menggunakan produk tersebut untuk memperoleh tujuannya dan seberapa puaskah pengguna terhadap pemakaiannya. Lebih lanjut Rubin \& Chisnell (2008:4), menyebutkan secara rinci bahwa untuk menerapkan metode usability testing, maka harus terdiri dari 5 komponen yaitu Usefulness (Kegunaan), Efficiency (Efisiensi), Effectiveness (Keefektifan)/Errors frequency, Learnability (Kemampuan dipelajari)/Memorability, dan Satisfaction (Kepuasan).

Uraian di atas menjelaskan bahwa untuk melihat hasil aplikasi yang dibangun dapat dilakukan pengujian aplikasi tersebut, salah satunya yaitu dengan metode usability testing (uji usability). Uji usability merupakan suatu metode pengujian aplikasi atau sistem yang mengacu pada bagaimana pengguna bisa mempelajari, menggunakan produk untuk memperoleh tujuannya dan seberapa puaskah pengguna terhadap pemakaian produk tersebut. Pengukuran usability dapat diterapkan dengan membuat seperangkat pertanyaan yang disajikan dalam bentuk koesioner.

\section{METODE PENELITIAN}

DFD merupakan salah satu alat bantu yang dapat digunakan dalam menggambarkan suatu jenis sistem yang dikembangkan. Melalui DFD sistem dapat lebih mudah untuk dipahami dan dimengerti secara sederhana dan mudah. DFD biasanya dibuat sebelum sistem tersebut dikembangkan secara berkelanjutan. Adapun bentuk DFD aplikasi yang dikembangkan dapat dilihat pada Gambar 1. 


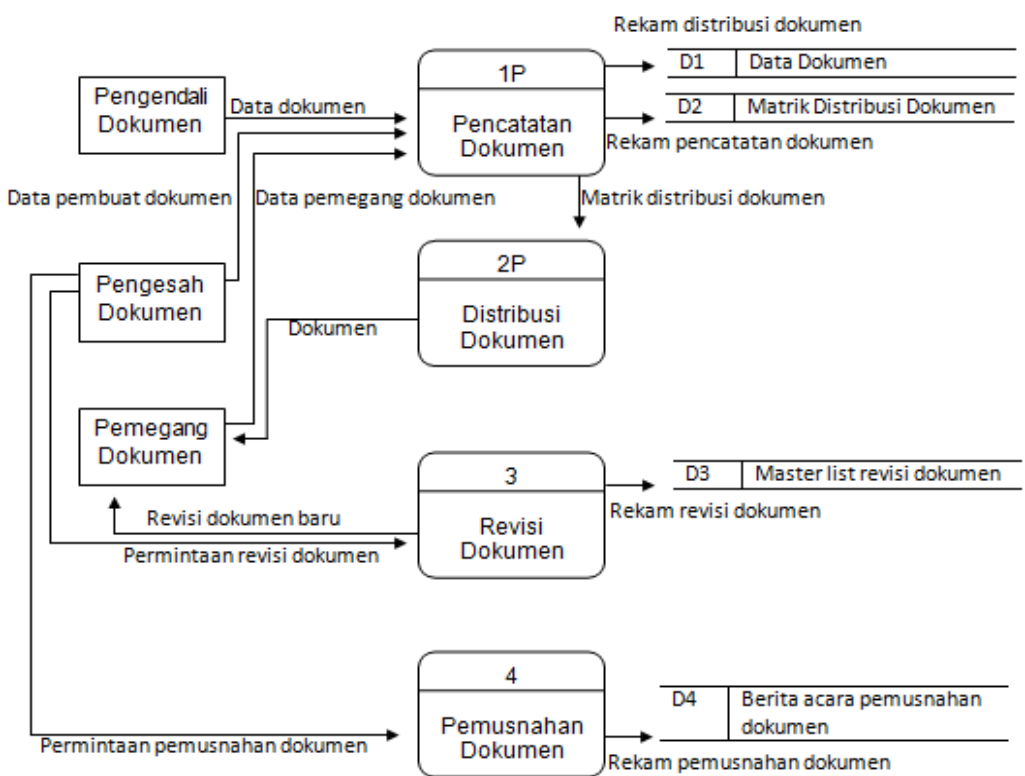

Gambar 1. Rancangan DFD

Basisdata merupakan hal terpenting saat pembuatan sistem yang berfungsi untuk menyimpan seluruh data atau kegiatan yang dilakukan pada sistem. Pada sistem yang dibangun basisdata disini digunakan untuk menyimpan seluruh dokumen ISO dan hal-hal terkait dengan sistem pengemdalian dokumen.

Data-data terkait akan disimpan dalam sebuah tabel yang saling berrelasi satu sama lain, diantaranya yaitu: tabel (1) user; (2) jabatan; (3) departemen; (4) pembuat dokumen; (5) dokumen; (6) order revisi dokumen; (7) revisi dokumen; (8) order pemusnahan dokumen; dan (9) pemusnahan dokumen. Seluruh tabel dan relasi antar tabel pada basisdata sistem pengendalian dokumen secara detail dapat dilihat pada Gambar 2.

\section{Gambar 2. Rancangan Basisdata}

\section{PEMBAHASAN}

Antarmuka aplikasi yang dibangun mengacu pada semua sistem yang telah direncanakan, mulai dari DFD, Basisdata bahkan Menu-Menu yang dapat diakses. Sebelum masuk pada inti aplikasi yang dibangun, pengguna diwajibkan melakukan Login terlebih dahulu yang berfungsi untuk mengetahui level pangguna yang akan masuk (user atau admin). Tampilah 
halaman Login secara detai dapat dilihat pada Gambar 4.

Setelah pengguna berhasil melakukan Login sesuai dengan levelnya, selanjutnya penguna akan diarahkan pada halaman berikutnya yang merupakan halaman utama aplikasi yang dibangun. Halaman utama antar muka aplikasi yang dikembangkan dapat dilihat pada Gambar 5 .

Pada ha pengguna proses $p$ beberapa aplikasi manajemer kesiswaan, konseling, Kakomli T

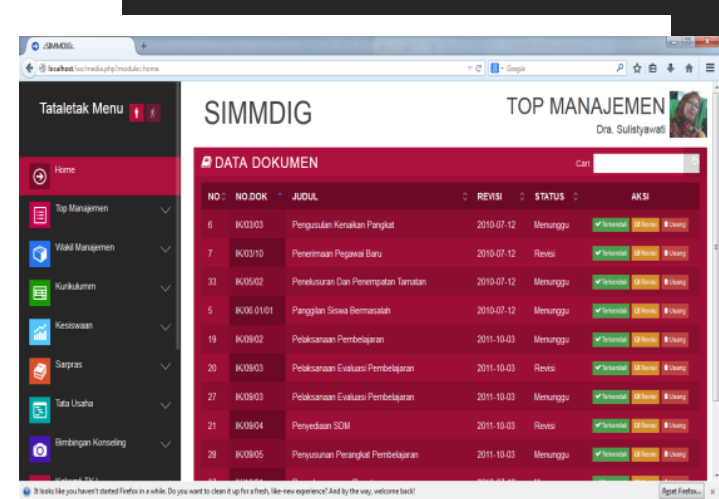

\section{Gambar 5. Halaman Utama Aplikasi}

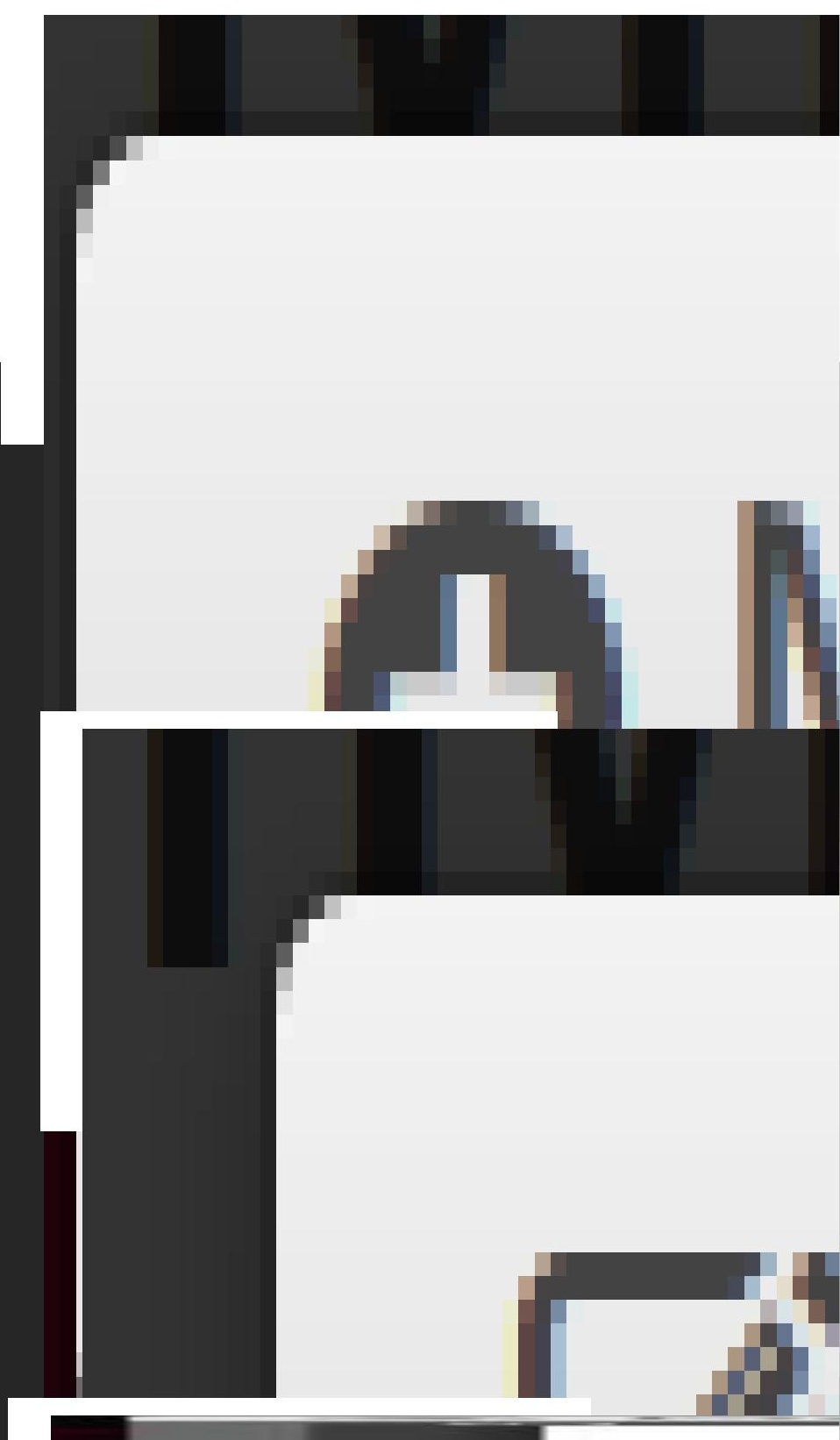

Gambar 8. Menampilkan Dokumen
Pada $h$ dapat men: simtem a secara deta dapat dilih 
dilakukan menggunakan produk yang dibangun terbukti dapat meningkatkan kinerja para pelaku manajemen dari semua departemen yang ada; (3) Tingkat efektifitas dan efisiensi waktu dengan menggunakan produk yang telah dibangun relatif lebih cepat saat dibandingkan dengan SMM ISO yang diterapkan sebelumnya; (4) Tingkat kepuasan dan kegunaan pengguna terhadap produk yang dibangun sangat tinggi, sehingga dapat disimpulkan bahwa pengguna merasa sangat puas dan merasa lebih mudah saat memakai produk yang dibagun.

\section{REFERENSI}

[1] Depdikbud. 1997. Pokok-Pokok Pikiran Keterampilan Menjelang 2020 dengan Perkembangan. Jakarta: Direktorat Dikmenjur Ditjen Dikdasmen.

[2] Depdiknas. 2002. Kerangka Kualifikasi Nasional Indonesia (KKNI) dalam Pengembangan Sumber Daya Manusia (SDM). Jakarta: Direktorat Ditmenjur.

[3] Indrajit, Richardus Eko. 2013. Evolusi Perkembangan Teknologi Informasi. (Online) (http://eko-indrajit.com. Diakses tanggal 24 November 2015).

[4] Kadir, Abdul. 2003. Pengenalan Teknologi Informasi. Yogyakarta: ANDI.

[5] Laudon, Kenneth C., \& Laudon, Jane P. 2007. Sistem Informasi Manajemen Mengelola Perusahaan Digital. Jakarta: Salemba Empat.
[5] Nugroho, Bunafit. 2005. Database Relasional dengan MySql. Yogyakarta: Andi

[6] Rahadi, Dedi Rianto. 2014. Pengukuran Usability Sistem Menggunakan Use Questionnaire Pada Aplikasi Android. Jurnal Sistem Informasi (JSI), 6(1):661671.

[7] Rubin, Jeffrey \& Chrisnell, Dana. 2008. Handbook of Usability Testing: How to Plan, Design and Conduct Effective Tests. Indiana: Wiley Publishing

[9] Sugiyono. 2003. Profesionalisasi Manajemen Pendidikan Kejuruan di Indonesia; Pidato Pengkuhan Guru Besar di Universitas Negeri Yogyakarta, 30Agustus-2003.

[10] Sugiyono. 2010. Metode Penelitian Pendidikan Pendekatan Kuantitatif, Kualitatif, dan R\&D.Bandung: Alfabeta.

[11] Sonhadji, Ahmad. 2013. Manusia, Teknologi, dan Pendidikan Menuju Peradaban Baru. Malang: Universitas Negeri Malang.

[12] Suprianto, Aji. 2007. Pengantar Teknologi Informasi. Jakarta: Salemba Infotek.

[13] Tampubolon, Daulat P. 2001. Perguruan Tinggi Bermutu. Jakarta: PT Gramedia Pustaka Utama.

[14] Wahyono, Teguh. 2004. Computer Base Information System (CBIS). (Online) (http://ilmukomputer.com. Diakses tanggal 24 November 2015). 